\title{
A Experimentação na Docência de Formadores da Área de Ensino de Química
}

\section{The experimentation in teaching trainers of the chemistry teaching area}

\author{
Fábio Peres Gonçalves e Carlos Alberto Marques
}

Resumo: Investigou-se, com formadores de professores atuantes em componentes curriculares da área de ensino de química, como a docência na licenciatura em química pode contribuir para a aprendizagem sobre a experimentação no ensino de ciências. Pretende-se colaborar na caracterização de possibilidades metodológicas para a abordagem da experimentação, na qualidade de um conteúdo da formação inicial de professores de ciências da natureza. A pesquisa se fundamentou, em parte, em pressupostos do educador brasileiro Paulo Freire, dos quais se originaram categorias a priori de análise. Foram realizadas entrevistas semiestruturadas com cinco formadores de professores atuantes em componentes curriculares da área de ensino química de diferentes cursos de licenciatura em química brasileiros. A análise das informações qualitativas foi conduzida pelos procedimentos da análise textual discursiva. Com isso, apontou-se, por exemplo, a presença de situações-limite que influenciam no processo de disseminação e apropriação de assuntos relacionados às atividades experimentais na formação inicial de professores de química. De modo que se faz relevante a problematização da experimentação em tal processo formativo como forma de enfrentar as situações-limite. Sinaliza-se também a necessidade de problematizar contradições nos conhecimentos e nas ações dos participantes da formação inicial, quais sejam, formadores das componentes curriculares de conteúdos específicos e integradoras e licenciandos. Face ao exposto nas análises, destaca-se que o relatado pelos formadores aponta, em certa medida, maneiras de abordar as atividades experimentais e que pode colaborar para favorecer a problematização das atividades experimentais na formação inicial de professores de química.

Palavras-chave: experimentação, formação de professores de química, docência na educação superior, Paulo Freire

\begin{abstract}
It was investigated, along with trainers of teachers working in curriculum components of chemistry teaching area, how the teaching degree in chemistry can contribute to learning about experimentation. It is intended to assist in the characterization of the methodological possibilities to the experimentation approach, in the quality of content in the initial training of natural science teachers. The research was based partly on assumptions of the Brazilian educator Paulo Freire which originated $a$ priori categories of analysis. Semi-structured interviews were conducted with five trainers of teachers working in curriculum components of chemistry teaching area from different degree courses in chemistry. The analysis of qualitative information was conducted by the procedures of discursive textual analysis. With this was pointed out, for example, the presence of limit-situations that influence in the dissemination process and ownership of issues related to experimental activities in the initial chemistry teacher training. So is relevant the questioning of the trial in such a formative process as a way to cope with limit-situations. It also signals the need to discuss contradictions in knowledge and actions of participants in the initial teacher training, namely, trainers of the curriculum components of specific and integrated undergraduate with the content. Given the above in the analysis, stands out that what was reported by trainer's points, in a certain way, ways to approach the experimental activities and that may contribute to foster the problematization of the trial in the initial chemistry teacher training.
\end{abstract}

Keywords: experimentation, chemistry teacher training, teaching in higher education, Paulo Freire.

Fábio Peres Gonçalves (fabio.pg@ufsc.br), licenciado em Química (Universidade Federal do Rio Grande - FURG), mestre e doutor pela Pós-Graduação em Educação Científica e Tecnológica (PPGECT) da Universidade Federal de Santa Catarina (UFSC), é docente do Departamento de Química e do PPGECT da UFSC Florianópolis, SC - BR. Carlos Alberto Marques (carlos.marques@ufsc.br), licenciado, bacharel e mestre em Química (UFSC), doutor em Ricerche in Scienze Chimiche (Universita degli Studi di Venezia - Itália), é docente do Departamento de Metodologia de Ensino e do PPGECT da UFSC. Florianópolis, SC - BR. Recebido em 17/12/2014, aceito 09/12/2015 
Pesquisas em ensino de ciências têm contribuído para caracterizar, direta ou indiretamente, compreensões sobre experimentação de participantes de cursos de educação superior em ciências da natureza (Antúnez; Pérez; Petrucci, 2008; Grandini; Grandini, 2004; Hirvonen; Viiri, 2002; Afonso; Leite, 2000). Esses trabalhos auxiliam, por exemplo, na construção de um quadro teórico das compreensões de licenciandos e formadores acerca do papel das atividades experimentais no ensino. Depreende-se dos resultados das investigações que as visões concernentes às atividades experimentais se encontram arraigadas em um entendimento empírico-indutivista de ciência. Assim, a obtenção de tal quadro teórico pode colaborar para que os formadores possam prever conhecimentos dos seus alunos relativos à experimentação e estruturar atividades que possibilitem problematizar tais conhecimentos. Em outras palavras, essas investigações podem favorecer melhor abordagem didática dos formadores em torno das atividades experimentais no ensino de ciências.

De outra parte, a experimentação na qualidade de um conteúdo da formação docente tem sido inexplorada em relevantes obras sobre atividades experimentais no ensino de ciências como aquelas organizadas por Psillos e Niedderer (2002) e Wellington (1998). Analogamente, ressalta-se o caráter incipiente da pesquisa em torno da docência na educação superior em química/ciências da natureza e do desenvolvimento profissional dos formadores de professores de ciências da natureza nos contextos brasileiro (Francisco; Queiroz, 2008; Brzezinski, 2006; Schnetzler, 2002) e internacional (Campanario, 2003). Ainda assim, evidencia-se que a prática de formadores de professores atuantes em componentes curriculares da área de ensino de química, por exemplo, busca enfrentar aqueles entendimentos empírico-indutivistas em torno da experimentação (Silva; Schnetzler, 2005) amplamente apontados pela literatura. Por outro lado, há indicativos de que as compreensões de professores da educação superior das áreas de ciências da natureza no que concerne à ciência, ao ensino e à aprendizagem carecem de coerência epistemológica entre si (Martínez; Benarroch, 2013; Benarroch; Marin, 2011).

Diante do exposto, considera-se importante elucidar práticas de formadores de professores de ciências da natureza em torno da experimentação no ensino, na qualidade de um conteúdo da formação docente. A caracterização e a problematização dessas práticas pode ser um modo de colaborar para a abordagem das atividades experimentais na formação inicial de professores. Para tanto, desenvolveu-se uma investigação com a seguinte questão de pesquisa: de acordo com formadores de professores atuantes em componentes curriculares da área de ensino de química (metodologia de ensino de química, prática de ensino de química etc.), como a docência na licenciatura em química pode contribuir para a aprendizagem sobre a experimentação no ensino de ciências? Cabe registrar explicitamente no que esta pesquisa não se constitui, isto é, em uma análise de compreensões de formadores de professores acerca da experimentação no ensino de ciências, uma vez que isso já vem sendo vastamente discutido na literatura e não contribuiria para renovar o cenário da pesquisa a respeito das atividades experimentais, aspecto necessário como sinalizam Hofstein e Mamlok-Naaman (2007). De outra parte, avalia-se que a pesquisa sobre as atividades experimentais no contexto da formação inicial de professores de química/ciências da natureza pode colaborar para a emergência de novos resultados e problemas associados à temática da experimentação. A investigação se fundamentou parcialmente em pressupostos progressistas de educação, apresentados a seguir.

\section{A formação docente no ensino de ciências interpretada por uma perspectiva progressista de educação}

De acordo com Delizoicov (2008), desde a década de 1980, pesquisadores em ensino de ciências têm desenvolvido trabalhos com base nas ideias do reconhecido educador brasileiro Paulo Freire. É possível encontrar na literatura atual diferentes articulações entre a perspectiva de educação defendida por este e o ensino de ciências (Santos, 2009; Gehlen; Auth; Auler, 2008; Auler et al., 2005). Chama-se a atenção também para as recentes articulações do pensamento do educador com a educação superior. Exemplos disso podem ser encontrados na Revista Lusófona de Educação que, em 2013, lançou uma edição especial sobre o assunto.

Em relação à formação docente, particularmente, destaca-se que entendê-la sob um viés progressista de educação implica não reduzir os professores a meros aplicadores de propostas de ensino alheias e descontextualizadas como defendem as premissas da racionalidade técnica (Schnetzler, 2002). Esse viés incentiva o efetivo envolvimento docente na produção das propostas de ensino e reconhece o professor como sujeito não neutro que, ao participar de processos de formação, traz conhecimentos que ajudam a dar significados aos objetos de estudo.

Uma das possibilidades de superar as premissas da racionalidade técnica pode ser a adoção da pesquisa como princípio formativo. A relação entre ensino e pesquisa é assinalada de forma positiva por Freire (1996), que reconhece na pesquisa um modo de intervenção educativa ao docente e ao discente, incluindo situações em que ocorre a participação direta dos investigados no processo de pesquisa:

Dizer que a participação direta, a ingerência dos grupos [...] no processo de pesquisa altera a "pureza" dos resultados implica na defesa da redução daqueles grupos a puros objetos da ação pesquisadora [...] a pesquisa como ato de conhecimento, tem como sujeitos cognoscentes, de um lado, os pesquisadores profissionais, de outro, os grupos [...] e, como objeto a ser desvelado, a realidade concreta. (Freire, 1981, p. 35) 
A investigação com princípio formativo inclui uma característica importante em um processo educativo que se entende dialógico, isto é, tem na problematização a origem do conhecimento, e sua presença é essencial seja em uma pesquisa, seja em qualquer outro ato educativo. Não obstante, é necessário analisar como se caracteriza uma problematização. Não se trata de problemas com o potencial de gerar, de forma obrigatória, conhecimento academicamente original. Nas palavras de Freire:

No fundo, em seu processo, a problematização é a reflexão que alguém exerce sobre um conteúdo, fruto de um ato, ou sobre o próprio ato, para agir melhor, com os demais na realidade. Não há problematização sem esta última (daí que a própria discussão sobre o além deva ter, como ponto de partida, a discussão sobre o aqui, que, para o homem, é sempre um agora igualmente). (Freire, 1977, p. 82-83)

Nessa perspectiva, o formador não mistifica a profissão para seus aprendizes, mas a problematiza enquanto os ensina (Freire; Shor, 1986). Por isso, não cabe enaltecer a experimentação como se ela fosse, por si só, a solução dos problemas do ensino de ciências. No entanto, como assinalado por Freire e Shor (1986), determinadas características nos processos formativos, a exemplo da hierarquização política do conhecimento, podem contribuir minimamente para a problematização. Uma característica própria da racionalidade técnica é valorizar, no percurso formativo, a predominância das componentes curriculares de conteúdo específico (química orgânica, química inorgânica etc.) em relação às componentes curriculares pedagógicas/ integradoras (didática das ciências, metodologia do ensino de química etc.). Além do mais, nessa perspectiva, as componentes curriculares da área de ensino se concentram mais no final do curso, com a função de incentivar, dentre outras, a aplicação descontextualizada de técnicas de ensino. Nessas condições, a racionalidade técnica favorece a hierarquia política do conhecimento na formação inicial de professores e colabora, sobremaneira, no estabelecimento e na permanência de vários problemas no desenvolvimento profissional docente, como o fato de cultivar uma prática pedagógica praticamente isenta de reflexões fundamentadas. Ou seja, pode-se afirmar que essas características da formação inicial são situações-limite que precisam ser problematizadas com a finalidade de se vislumbrar um inédito viável (Freire, 2005). Acerca das situações-limite, Freire (2005, p. 104-105) argumenta que:

[...] as situações-limites, [...] não devem ser tomadas como se fossem barreiras insuperáveis, mais além das quais nada existisse. No momento mesmo em que os homens as apreendem como freios, em que elas se configuram como obstáculos à sua libertação, se transformam em 'percebidos destacados' em sua 'visão de fundo'. Revelam-se, assim, como realmente são: dimensões concretas e históricas de uma dada realidade.

No contexto da pesquisa em ensino de ciências, Coelho (2005), por exemplo, destaca que a falta de laboratórios ao inibir a promoção de atividades experimentais pode ser caracterizada como uma situação-limite. A autora, ao mesmo tempo, sinaliza formas de enfrentá-la - exploração de materiais alternativos etc. - , o que se caracteriza como o inédito viável: aquilo que está além das situações-limite (Freire, 2005).

Em suma, de acordo com um viés progressista, a formação de professores precisa investir, em parte, na problematização que, além de favorecer a apreensão do conhecimento discente, deve fomentar a necessidade de apropriação de um conhecimento (Delizoicov, 2005) que possa contribuir para o enfrentamento de situações-limite. No entanto, a presença desses aspectos na docência dos formadores e dos professores da educação básica não é uma questão trivial.

\section{Caminhos metodológicos}

Foram desenvolvidas entrevistas semiestruturadas com cinco formadores de professores de química atuantes em componentes curriculares integradoras e cinco de conteúdo específico. Os roteiros para as entrevistas semiestruturadas com os formadores das componentes curriculares de conteúdos específicos e das integradoras foram diferentes. Os resultados vinculados à análise das entrevistas com os formadores de conteúdo específico foram publicados preliminarmente sob o mesmo referencial teórico (Gonçalves; Marques, 2013). O critério para convidá-los a participar da investigação foi o fato de terem publicado, como autor e/ou coautor, pelo menos dois artigos com propostas de experimento na seção Educação do periódico Química Nova, publicação da Sociedade Brasileira de Química. A análise dessas propostas de atividades experimentais para a educação superior em química constituiu etapa prévia da pesquisa (Gonçalves; Marques, 2011; 2012b). Mais especificamente foram analisados, por meio de artigos com propostas de experimentos de química para a educação superior, discursos pedagógicos, epistemológicos e ambientais relativos à experimentação presentes entre docentes de química atuantes nesse nível educacional. A opção por docentes com autoria e/ ou coautoria ocorreu devido ao fato de se buscar sujeitos interessados na dimensão pedagógica da experimentação. Desse modo, foram identificados 38 docentes que publicaram duas ou mais vezes como autor/coautor, de modo que os 5 pesquisados representam $13 \%$ do total.

Para convidar os formadores das componentes curriculares integradoras, adotou-se um critério similar, isto é, terem algum tipo de publicação a respeito da experimentação no ensino de ciências (artigo completo em anais de eventos, artigo em revista, livro ou capítulo de livro, livro didático, palestras, 
conferências e mesas redondas) como autor/coautor ou, ainda, a orientação de teses e/ou dissertações relativas ao tema. As informações sobre as publicações dos docentes foram obtidas com o auxílio da Plataforma Lattes do Conselho Nacional de Desenvolvimento Científico e Tecnológico (CNPq). Não foi possível utilizar como critério de convite para esses formadores a publicação de propostas de experimento na Química Nova, pois não publicaram artigos de tal natureza no periódico em questão ou de fundamentação teórica acerca da experimentação no ensino de ciências com intensidade semelhante a dos formadores das componentes curriculares de conteúdo específico. Estes estiveram na autoria de 102 artigos com propostas de atividades experimentais na seção Educação da Química Nova no período analisado. Por outro lado, foi inexpressiva a autoria de propostas de atividades experimentais na referida seção por parte dos formadores das componentes curriculares integradoras, o que poderia colaborar para a identificação dos entrevistados se fosse utilizado como critério para convite desses profissionais a publicação dos mencionados artigos no periódico.

Tanto no caso dos formadores das componentes curriculares integradoras quanto dos que lecionam em componentes de conteúdo específico, utilizou-se como critério para o convite o fato de suas publicações abrangerem os últimos 10 anos, considerando a data de início desta investigação. O critério de publicação se justifica pela intenção de buscar sujeitos que possuam vivência e problematizem o que se pretende conhecer (Silva; Schnetzler, 2005). Soma-se a isso o fato de esses sujeitos, em diferentes instâncias, serem difusores de discursos que, pelo menos em parte, refletem a produção da investigação em ensino de ciências acerca da experimentação. Em vista desses critérios, os professores se caracterizaram por pertencer a diferentes instituições de educação superior no Brasil. O número de docentes das componentes curriculares integradoras convidados para participar das entrevistas se baseou no número de docentes das componentes de conteúdo específico. Todos os formadores das componentes curriculares integradoras eram doutores e pesquisadores em ensino de química, sendo que três lecionavam em instituições públicas e dois, em privadas. Como já destacado, os resultados relativos à análise das entrevistas com os formadores de conteúdo específico foram publicados previamente, de modo que neste trabalho se apresenta a análise das entrevistas com os formadores das componentes curriculares integradoras. Esses profissionais atuam em diferentes componentes curriculares da área de ensino de química (estágio em química, metodologia do ensino de química etc.) de cursos de licenciatura em química. É preciso ressaltar que, na diversidade dos referidos cursos existentes no Brasil, nem sempre componentes curriculares da área de ensino de química têm formadores com doutorado nas áreas de ensino de química/ciências ou educação e que possuam a graduação em licenciatura em química ou áreas afins. Não é raro encontrar pedagogos com doutorado em educação ou bacharéis em química com doutorado na mesma área como docentes responsáveis pelas componentes curriculares da área de ensino de química. No entanto, esse não foi perfil dos entrevistados. Diante do exposto, pode-se concluir que formadores presentes nas licenciaturas em química podem ter uma formação bastante variada. Em síntese, além dos licenciandos, outros sujeitos das licenciaturas em química são os formadores das componentes curriculares de conteúdos específicos, das integradoras e das pedagógicas e que, portanto, têm diferentes origens de formação. Na análise das entrevistas amiúde, faz-se referência a esses sujeitos.

A análise qualitativa das informações obtidas nas entrevistas foi orientada pelos procedimentos da análise textual discursiva (Moraes; Galiazzi, 2007) que possui três etapas: unitarização, categorização e comunicação. Na primeira etapa, ocorreu a fragmentação dos textos, originados da transcrição das entrevistas, em unidades de significado. A categorização é um processo de natureza classificatória em que as unidades de significado são agrupadas de acordo com suas semelhanças semânticas. Nesta pesquisa, utiliza-se um processo de análise misto (Moraes; Galiazzi, 2007), isto é, com categorias emergentes e a priori. As categorias a priori estão baseadas especialmente na perspectiva progressista de educação adotada e as categorias emergentes dialogam de forma mais intensa com outros interlocutores para além daqueles da perspectiva progressista de educação assumida. A comunicação decorre da etapa de categorização a partir da qual se produz o metatexto com ênfase descritiva e interpretativa. Nos trechos transcritos das entrevistas, os professores estão representados por letras do alfabeto e números que os diferenciam (P1... P5).

A análise textual discursiva se encontra em harmonia com os pressupostos do viés dialógico e problematizador de educação expressado anteriormente, pois considera, por exemplo, que as aprendizagens elaboradas nas análises podem vir a se constituir em uma intervenção nos discursos e realidades relacionados aos textos analisados (Moraes; Galiazzi, 2007). É o que se tem denominado de qualidade política da análise textual discursiva, assumida nos objetivos desta investigação e igualmente presente na perspectiva progressista de educação adotada. $\mathrm{Na}$ literatura, encontram-se outras possibilidades de aproximação entre a análise textual discursiva e o referencial dialógico e problematizador de Paulo Freire (Torres et al., 2008).

A seguir, são apresentadas as categorias de análise: situações-limite; contradições acerca da experimentação; o espaço de atuação do professor e do químico; o respeito ao conhecimento inicial dos licenciandos sobre a experimentação; o movimento contra-hegemônico em relação aos experimentos ilustrativos; a abordagem da experimentação relacionada com a história e a epistemologia da ciência; e conhecimentos sobre a experimentação: permanências e transformações. Reitera-se que os resultados apresentados aqui são complementares aos da análise das entrevistas com os formadores das componentes curriculares de conteúdo específico, feita à luz do viés progressista de educação explicitado (Gonçalves; Marques, 2013). 
Nessa referência, é possível encontrar uma discussão mais ampla acerca do referencial teórico ligado ao viés dialógico e problematizador de Paulo Freire associado à formação docente e às atividades experimentais e, em outro trabalho (Gonçalves; Marques, 2012a), estende-se a apresentação do referencial dos procedimentos analíticos, no qual se analisaram os processos de apropriação do discurso sobre a experimentação no ensino dos formadores atuantes em componentes curriculares de conteúdo específico e as propostas de professores de componentes curriculares integradoras relativas ao como abordar as atividades experimentais na qualidade de um conteúdo da formação inicial. Outras informações metodológicas podem ser obtidas nesses trabalhos.

\section{Análise das informações qualitativas}

A seguir, são apresentadas as categorias de análise. A categoria situações-limite apresenta as subcategorias a coletividade e a cumplicidade reprimidas e as estruturas institucionais. Situações-limite se constituem na categoria a priori e as demais se caracterizaram como categorias emergentes.

\section{Situações-limite: a coletividade e a cumplicidade reprimidas}

Os formadores reconheceram a ausência de um trabalho coletivo e de cumplicidade entre os diferentes sujeitos da licenciatura no que concerne à abordagem das atividades experimentais no ensino de ciências e, por conseguinte, implicações dessa ausência em tal abordagem. Interpreta-se justamente, como uma situação-limite, a falta de cumplicidade entre esses profissionais acerca da experimentação: "A gente consegue um diálogo bom na área de ensino [...], sabe os enfoques que os nossos colegas trabalham nas disciplinas deles com relação a isso. Com relação a outras disciplinas [conteúdos específicos], não tem diálogo [...]" (P5). Está implícito na abordagem do formador que uma aprendizagem efetiva acerca das atividades experimentais poderia envolver não somente a atuação de formadores de componentes curriculares integradoras como também daqueles de componentes curriculares de conteúdo específico, visto que a metodologia que orienta os experimentos desenvolvidos pelos últimos pode ser exemplar para os professores de química da educação básica. Como diz Freire (1996), a corporeificação da palavra pelo exemplo é um aspecto necessário na prática educativa. Isso não significa atribuir aos professores das componentes curriculares de conteúdo específico a responsabilidade absoluta pelo problema da aprendizagem sobre a experimentação.

Os próprios formadores admitem que a forma como as instituições de educação superior se organizam favorece a inexistência e a resistência ao trabalho coletivo: "[...] vejo que há dificuldade ainda, e isso talvez passe pela falta de diálogo, que é difícil fazer diálogo com grupos da área específica [...].
As reuniões são reuniões administrativas" (P4). A insuficiência de reuniões de natureza pedagógica - em geral, são administrativas - nas instituições de educação superior é identificada no fragmento e desvela o cenário de raras oportunidades para a aprendizagem de assuntos relativos à docência como a experimentação. O modo de as instituições se organizarem propicia o trabalho individualizado dos formadores e a impermeabilidade às inovações e discussões a respeito das atividades experimentais. A forma de organização institucional também se constitui, por si só, como discutiremos posteriormente, em uma situação-limite em relação à docência e à experimentação no ensino. Cada professor é responsável pela componente curricular que leciona e, nas instituições públicas, pelo menos, parece haver certo tipo de cultura do silêncio (Freire; Shor, 1986), na qual raramente se problematizam de forma sistematizada as práticas docentes. Ainda que haja processos de formação docente em instituições de educação superior para professores ingressantes, de acordo com investigação desenvolvida por Bazzo (2007), há indicativos de falta de comprometimento desses sujeitos com tais processos, bem como de resistência por os interpretarem como uma imposição institucional. O exposto pela autora sugere que, embora o apoio das instituições de educação superior seja essencial, é preciso envolver os professores nos diferentes momentos da formação docente como coautores e não meros receptores. Apesar de críticas à racionalidade técnica, não se pode excluir a possibilidade de esta ainda orientar a formação oferecida aos docentes da educação superior.

Determinados professores e alunos dão a entender que compartilham uma visão de ensino e aprendizagem. Isso se evidencia quando os formadores procuram colocar em xeque, por meio de práticas inovadoras, as compreensões dos licenciandos acerca da experimentação:

"[...] as minhas atividades de experimentação [...], elas tinham muito a questão do aluno dizer, do aluno falar, não é? Mas, era muito difícil [...] pro sujeito entender o que eu tava querendo [...]. Eu não sei se o que a gente fala tem repercussão na sala de aula [...].” (P1)

O desenvolvimento de experimentos pelos formadores pode provocar resistências nos alunos devido ao fato de essas atividades, em certas ocasiões, romperem com uma proposta já conhecida. O mesmo formador acrescenta: "Mas eles [licenciandos] estão distantes da discussão da educação [...], é como eles estão olhando para um lado, e a gente quer mostrar o outro [...]. Tão lá olhando pro lado da lista de exercício [...] de Química Geral [...]” (P1). A racionalidade técnica, traduzida no modelo 3+1 de formação inicial - componentes de curriculares de conteúdo específico se concentram nos três primeiros anos da licenciatura e as pedagógicas e integradoras, no último ano -, tem efeitos sobre o modo como os licenciandos entendem os conhecimentos, pois valorizam, de acordo com o pesquisado, 
os conhecimentos de química em detrimento daqueles da área de ensino. Todavia, o depoimento é do docente de um curso em dissonância com o modelo $3+1$. Portanto, há um indicativo de morosidade entre os licenciandos em romper, da mesma forma que a estrutura curricular do curso no qual estão inseridos, com os pressupostos da racionalidade técnica. De outra parte, a morosidade pode ser explicada pelo fato de que, mesmo sob reformulação curricular que ultrapassa o modelo de $3+1$, a licenciatura em química continua com formadores que acreditam em uma hierarquia excludente em termos de conhecimento, de modo que não há um abandono total das premissas da racionalidade técnica, e os graduandos permanecem influenciados por tais premissas. Tal situação pode ser interpretada à luz do que expõem Freire e Shor (1986), ou seja, existe uma hierarquia política do conhecimento. Na formação de professores, há conhecimentos pouco valorizados em detrimento de outros. Um dos poucos valorizados no contexto da racionalidade técnica é aquele associado à área de ensino de química. Pode-se afirmar que essas características da formação inicial são, por si só, situações-limite que precisam ser problematizadas a fim de se vislumbrar um inédito viável (Freire, 2005).

$\mathrm{O}$ mesmo formador identifica a inexistência de uma cumplicidade efetiva entre o docente da educação superior e o da escola:

"Eu tô tentando articular o professor da escola com o licenciando pra virem aqui juntos trabalhar [no grupo de formação permanente]. Mas, é muito separado [...], o aluno chega lá, o professor não tá nem preparado pra entender o que está sendo posto [sobre experimentação] [...]. Muitas vezes, o professor pede uma determinada prática pro aluno assim: '- Ah, tô trabalhando isso, funções, faz uma prática' [...] Aquela velha questão: '-faz uma prática motivadora'." (P1)

O processo de ensino e aprendizagem das atividades experimentais em interação com a escola é uma condição importante, embora possua uma limitação, qual seja, o fato de os professores das escolas - nas quais os licenciandos interagirão - não compartilharem visões acerca das atividades experimentais com os formadores, aspecto presumível diante da problemática da formação de professores. O formador localiza inclusive uma compreensão comum dentre os docentes: a crença na experimentação como motivadora (Hodson, 1994). É um indício de que na aproximação entre a instituição de educação superior e a escola é relevante ocorrer a problematização também do entendimento de professores da educação básica a respeito do papel da experimentação. Por outro lado, há uma probabilidade de essa problematização encontrar situações-limite para sua concretização. Independentemente disso, é indispensável formar licenciandos suficientemente críticos para apreender as limitações das práticas e dos discursos dos professores com os quais interagem ao longo da formação inicial. Acrescenta-se a possibilidade de a simples presença dos licenciandos na escola contribuir, de alguma forma, para a aprendizagem dos professores. Tal possibilidade não elimina a necessidade da problematização das atividades experimentais na formação docente.

Os investigados identificaram, portanto, aspectos - entendidos como situações-limite - relacionados com a coletividade e a cumplicidade, os quais podem influenciar no processo de aprendizagem acerca das atividades experimentais no ensino de ciências. Um dos aspectos destacados é o não compartilhamento de visões sobre a experimentação entre os formadores das componentes curriculares de conteúdo específico e das integradoras. Esses últimos sinalizam que os licenciandos podem não ser cúmplices de suas práticas pedagógicas, cujo escopo é inovar as atividades experimentais. A cumplicidade entre formadores e professores das escolas na abordagem da experimentação com os licenciandos também foi apontada como um aspecto problemático. O enfrentamento desses aspectos, que constituem uma situação-limite, parece estar associado com a problematização das atividades experimentais no processo de desenvolvimento profissional dos próprios formadores atuantes em componentes curriculares de conteúdos específicos (Gonçalves; Marques, 2013). Sumarizando, tanto a problematização das atividades experimentais quanto dos constituintes da situação-limite aqui delineada são ações importantes para os processos formativos.

\section{Situações-limite: as estruturas institucionais}

As estruturas institucionais - da escola e das instituições de educação superior formadoras de professores -, especialmente em suas dimensões física e organizacional, foram citadas como problemas que podem estar ligados a conteúdos abordados sobre a experimentação, bem como ao modo de ensiná-los e aprendê-los. A carência de recursos materiais nas escolas é um aspecto considerado na proposição de materiais alternativos para a realização de experimentos:

"[...] a gente trabalha muito é o recurso [...], materiais a serem utilizados, que podem ser materiais simples [...]. Pra ver como eles podem realizar experimento sem ter na escola materiais [...]. Ou [...] são laboratórios empoeirados, fechados [...], o professor pode fazer isso, não precisa fazer no laboratório." (P4)

A falta de laboratórios suficientemente estruturados nas escolas brasileiras é uma das situações-limite para os professores desenvolverem experimentos (Coelho, 2005). Os chamados materiais alternativos podem contribuir para vislumbrar o inédito viável, isto é, a promoção de atividades experimentais nas escolas. Sabe-se que houve diversas tentativas históricas de inserção do laboratório didático no currículo escolar nacional, 
mas que fracassaram, possivelmente porque desconsideraram aspectos como as condições de trabalho do professor e seus conhecimentos acerca da experimentação - em geral, pouco fundamentados nas produções acadêmicas atuais na área de ensino de ciências.

Conforme a análise das entrevistas com os formadores das componentes curriculares de conteúdo específico, estes também incentivam a utilização de tais materiais em suas aulas (Gonçalves; Marques, 2013). De certo modo, a estrutura física das escolas exerce influência na abordagem da experimentação de ambos os formadores. Contudo, há discrepâncias no modo de entender esse assunto por parte dos professores que ensinam química e daqueles das integradoras. Isso pode estar associado ao modo de organização interna da instituição que desfavorece a aproximação entre os profissionais como já sinalizado anteriormente.

Outra característica organizacional das instituições de educação superior que contribui para o cenário problemático da experimentação é o fato de os docentes de componentes curriculares de química não estarem obrigatoriamente em consonância com a proposta curricular do curso: "[...] a gente tem uma coordenação que coordena o curso, mas ela não interfere na sua atuação em sala de aula. Então, quem define como é que deve ser a disciplina de química analítica quantitativa é a área de química analítica [...]" (P5). Entendemos que o problema explicitado está relacionado a outro, qual seja, a docência como um território privado (Zabalza, 2004). Assim, a experimentação é ensinada como cada professor compreende que deva ser, inclusive aqueles das componentes curriculares integradoras. Em suma, a organização institucional colabora para a não realização de um trabalho mais coletivo em torno da abordagem das atividades experimentais.

Depreende-se do exposto que tanto a estrutura da escola quanto das instituições de educação superior, sobretudo suas dimensões física e organizacional, têm influências múltiplas no processo de ensino e aprendizagem da experimentação. Essas estruturas foram interpretadas como uma situação-limite e precisam ser problematizadas.

\section{Contradições acerca da experimentação}

Os formadores das componentes curriculares integradoras, em parte, apreendem e abordam contradições relacionadas à visão de experimentação dos licenciandos e demais participantes da licenciatura em química. Um exemplo é o entendimento da experimentação como a solução dos problemas do ensino de ciências, mas que não é desenvolvida nem quando há laboratório:

\footnotetext{
"Eu tenho [...] tentado problematizar a teoria dos alunos sobre a experimentação. Esse é meu conteúdo básico. Problematizar essa ideia que eles têm de que a experimentação vai resolver os problemas da escola e, ao mesmo tempo, eles não conseguem
}

fazer na escola [...]. Nem quando tem um super laboratório [...]. Tem escolas com um laboratório excelente que nunca foi usado [...].” (P1)

A situação relatada pelo formador sugere que não é a presença ou a ausência de laboratórios nas escolas, por si só, o fator determinante da realização de experimentos. A contradição revelada pelos licenciandos e professores da escola pode estar relacionada a situações-limite, como as precárias condições de trabalho dos docentes brasileiros, para além da ausência ou não de laboratório. Não parece, portanto, que a contradição mencionada seja de responsabilidade única daqueles que deveriam realizar os experimentos. Outro formador compartilha dessa compreensão:

"[...] eles não acreditam, mas é a única forma que eles sabem [...], é aquela coisa assim, pode ser até que eu não acredite do ponto de vista lógico [...]. Eu não acredito que o roteiro é a melhor forma, mas é a única forma que eu conheço. Eaí é aquela coisa do professor que repete práticas vivenciadas. Isso é muito forte, a gente sabe, principalmente no início ele repete ipsis litteris as práticas que ele vivenciou. Raros são aqueles que conseguem [...] não repetir, entendeu?" (P3)

O professor justifica o contraditório conhecimento inicial de seus alunos ao criticarem os experimentos realizados com base em roteiros estruturados pelos formadores das componentes curriculares de conteúdo específico e, ao mesmo tempo, proporem atividades experimentais semelhantes no estágio ou ainda na docência. Não parece um absurdo absoluto supor que problemas no currículo da formação inicial de professores de química somem em favor dessa contradição. Tais problemas, como a influência da racionalidade técnica, constituem-se em situações-limite desfavoráveis às aprendizagens dos licenciandos sobre conteúdos relativos à experimentação, uma vez que essas aprendizagens seriam frutos de uma efetiva interlocução com a literatura e a escola. A desarmonia entre a proposição dos formadores das componentes curriculares integradoras com os experimentos realizados em componentes curriculares de química na formação inicial é um assunto abordado por um dos pesquisados:

“[...] nós convivemos com essas contradições [...] inclusive tem, às vezes, doutor [...] que ele desenvolve pesquisa [...]. Mas, quando ele tá em sala de aula, ele é extremamente tradicional. E eu costumo trazer esse fato pra sala de aula. [...] E aí eu até chego a afirmar, às vezes, [...]: - é tão estranho que um doutor que trabalha com pesquisa, [...] que ele reconstrói o seu próprio conhecimento pesquisando, não ouvindo alguém dizer, mas fazendo, 
experimentando, lendo, pesquisando. E quando ele vai à sala de aula, ele só vai lá falar. Ele não leva essa consciência que ele tem de como se constrói conhecimento com a pesquisa pra sala de aula. (P4)

A contradição identificada pelo formador e estudada com os licenciandos pode auxiliar na problematização das atividades experimentais às quais foram submetidos como alunos, e também na análise de analogias entre a experimentação na ciência e em sala de aula, no intuito de localizar na maneira de realizar experimentos na ciência, aspectos importantes para propiciar a aprendizagem discente no laboratório didático. Como destaca Delizoicov (2000), as discussões epistemológicas promovidas pelos formadores podem fomentar uma análise crítica dos licenciandos em relação às aulas às quais são submetidos na graduação. $\mathrm{O}$ olhar epistemológico na análise é essencial para não incorrer em analogias inadequadas, tal como aquela cristalizada em materiais didáticos e que associam um método científico infalível aos experimentos a serem desenvolvidos nos laboratórios didáticos. Os docentes podem realizar, às vezes, analogias entre o trabalho no laboratório de pesquisa e o laboratório didático como destaca, de forma implícita, o pesquisado: "Aquele professor que trabalha com muitos projetos de pesquisa e tudo, já tem uma visão mais aberta, porque tá habituado a interagir com aluno em projetos" ( $\mathrm{P} 4)$. Os próprios formadores das componentes curriculares de conteúdo específico, por isso, poderiam vivenciar formações que explorassem analogias entre o seu trabalho como cientista e docente. Reafirma-se, contudo, a necessidade de não confundir, nas analogias sugeridas, as funções pedagógicas e epistêmicas da experimentação.

Se os formadores das componentes curriculares de conteúdo específico - que, em geral, vivenciam/vivenciaram a pesquisa em laboratório - não desenvolvem experimentos com base em discussões contemporâneas da didática das ciências, é preciso refletir sobre os motivos que levam os licenciandos de iniciação científica em química a aprenderem positivamente sobre as atividades experimentais por meio de tal introdução. Nessa direção, um dos formadores relata a crença de um licenciando na iniciação científica como importante para a sua aprendizagem a respeito da experimentação:

"[...] um dos meus alunos falou [...] que ele conseguia dar conta de entender o conceito, porque ele tinha feito iniciação científica [...] e que isso tinha sido muito importante pra ele, porque aí ele conseguia ver a aula prática não só enquanto uma receita, mas enquanto um caderninho de protocolo [...]. Onde ele fazia não dava certo, ele fazia de novo, não dava certo, ele trocava os reagentes, ele trocava as quantidades. Ou seja, essa vivência de laboratório deu a ele uma visão epistemológica mais apropriada." (P3)
A caracterização do formador é, em certa medida, contraditória com o cenário exposto pelos investigados. Ou seja, se os docentes das componentes curriculares de química que vivenciaram e/ou vivenciam mais intensamente o laboratório de pesquisa não obrigatoriamente realizam analogias adequadas entre o seu trabalho como pesquisador e o de professor, é preciso refletir sobre o porquê da vivência no laboratório de pesquisa proporcionar aos estudantes de iniciação científica uma analogia adequada. Sobretudo, pelo fato de os orientadores serem professores nos laboratórios de ensino cujas abordagens, às vezes, podem contribuir minimamente para a aprendizagem. Essas considerações não significam uma negação, em absoluto, da possibilidade apontada pelo formador. Admite-se que os alunos de iniciação científica podem fazer as analogias, até as inadequadas. No entanto, existe a probabilidade de as aprendizagens relativas à experimentação também serem catalisadas por uma abordagem nas componentes curriculares integradoras de exploração de analogias entre os experimentos científicos - seja na iniciação científica ou em outros cenários de pesquisa - e os didáticos, mas não obrigatoriamente pela iniciação científica. Contrariamente, pode-se desconsiderar o papel do conhecimento sistematizado, produzido pelas pesquisas em ensino de ciências, para apropriação e análise crítica a respeito da experimentação. A valorização demasiada da iniciação científica - não é o caso do investigado - poderia remeter à ideia de que se aprende principalmente pela prática.

Enfim, os docentes das componentes curriculares integradoras ressaltaram a relevância de abordar contradições relacionadas à experimentação. Uma contradição está associada com o fato de os professores acreditarem na experimentação, apesar de não as realizarem mesmo quando há laboratórios nas escolas. Outra contradição é a proposição de experimentos pelos licenciandos semelhantes àqueles desenvolvidos pelos docentes dos cursos de graduação, ainda que, às vezes, os critiquem. Essas atividades também são tomadas pelos investigados como constituintes de uma contradição devido ao modo como são promovidas, isto é, se nos laboratórios de pesquisa parece haver uma aprendizagem mais efetiva, não se pode afirmar que isso ocorra nos laboratórios de ensino, caso contrário, a experimentação não seria um problema de pesquisa. Há mais uma contradição de acordo com investigados: a crença na iniciação científica como favorecedora de aprendizagens positivas sobre a experimentação, embora isso não aconteça com os docentes das componentes curriculares de química que vivenciam a pesquisa (Gonçalves; Marques, 2013). Parece salutar apreender essas contradições na formação docente e no desenvolvimento profissional dos formadores com vistas a problematizá-las.

\section{O espaço de atuação do professor e do químico}

As justificativas em relação ao que selecionar ou excluir da abordagem sobre a experimentação no ensino de química 
apareceram de forma mais tácita na fala dos docentes. Um critério mencionado foi o futuro contexto de atuação dos licenciandos e, nesse caso, foram consideradas as limitações de infraestrutura das escolas:

"Teve outra discussão que nós tivemos [...]. O nome era 'experimentos em microescala' [...], mas isso nunca me cativou [...], pra fazer em microescala, tu precisas equipamento [...], o equipamento, de repente, é tão caro quanto o equipamento grande [...].” (P1)

O formador aponta o problema de recursos na escola como um fator limitante para desenvolver experimentos em microescala e, por conseguinte, não aborda essa modalidade de atividade experimental entre os licenciandos. Na compreensão do docente, é um artefato que não auxilia o enfrentamento do problema relativo à não realização de atividades experimentais na educação básica, apesar da sua importância na redução de resíduos. O argumento utilizado para não usar experimentos em microescala é o mesmo que justifica a escolha pelos materiais alternativos e o incentivo na formação inicial ao seu emprego.

Os espaços da escola e de ação do químico, isto é, o laboratório como um lugar de produção de conhecimentos, também justificariam a abordagem de outros assuntos sobre a experimentação:

"E a gente vai trabalhar com eles muito na perspectiva de experimentação pro ensino médio [...], eles devem saber preparar um experimento, eles devem saber avaliar um roteiro experimental, avaliar a periculosidade [...]. Avaliar a questão de resíduos que hoje se coloca como tão importante [...], o enfoque é: como é que você, enquanto professor, realiza experimentação na escola, seja no laboratório ou na sala de aula? [...] Qual é o objetivo da experimentação naquele contexto?” (P5)

No fragmento, aparece a abordagem de questões mais contemporâneas na discussão a respeito da experimentação no ensino de química, quais sejam, a preocupação com o tratamento de resíduos e a periculosidade dos experimentos no ambiente escolar, as quais podem estar associadas com o fomento à formação de atitudes e valores vinculados a questões ambientais (Silva; Machado, 2008). Ainda a respeito do laboratório, outro formador expõe:

"[...] a química tem enquanto o seu contexto de profissão, de validação [...] a experimentação [...], você pode usar este mote aí pra trazer por vários outros motivos. Ah, porque ela ajuda na criação de um contexto argumentativo, pra que a aula [...] Saia do lugar, não fique sem uma base empírica, vamos dizer assim. Acho que essa coisa da base empírica ainda é muito forte e é muito necessária [...].” (P3)

No fragmento, chama-se a atenção para a relevância da dimensão empírica que, segundo epistemólogos contemporâneos como Bachelard (1996), cumpre um papel importante na construção do conhecimento químico. Assim, supõe-se que o processo de ensino e aprendizagem da química ocorra de forma semelhante. Fica implícita a compreensão de que a produção de conhecimento nos laboratórios - e não exclusivamente neles - se insere em um contexto argumentativo. Tal contexto precisaria, da mesma forma, estar presente nos laboratórios didáticos de modo a favorecer a aprendizagem. Logo, o critério apontado pelo formador não significa dizer que, para aprender ciência por meio de experimentos, é necessário utilizar os mesmos métodos ou percorrer os mesmos caminhos dos cientistas.

A escola na qualidade de espaço de atuação dos professores de química, portanto, influencia na seleção dos formadores sobre o que ensinar a respeito da experimentação no ensino de química. A infraestrutura da escola, por exemplo, tem implicações na proposição dos materiais utilizados nos experimentos. O laboratório, na condição de espaço de produção do conhecimento químico, foi igualmente apontado como critério para escolher os conteúdos relativos à experimentação.

\section{0 respeito ao conhecimento inicial dos licenciandos sobre a experimentação}

Os professores das componentes curriculares integradoras relataram ações que expressam suas intenções de apreender tenazmente o conhecimento dos licenciandos acerca da experimentação. Esse conhecimento inicial também justifica a escolha por determinados conteúdos relativos às atividades experimentais em detrimento de outros. Tal critério de eleição apareceu, na maioria dos casos, implicitamente no discurso dos formadores. Foi recursiva a sinalização de uma abordagem de caráter epistemológico devido aos conhecimentos dos licenciandos:

“[...] existem as ciências como a química que historicamente foram feitas mediante a participação de laboratório. [...] as pessoas já sabem que [...], de certa forma, os químicos constroem esse conhecimento em laboratório, [...] provavelmente com uma visão muito ingênua ainda de que o cientista vai lá descobrir essas verdades já inscritas na natureza antes [...]. Eu não quero com isso dizer que nós tenhamos que manter aquela visão [...] ingênua de que o cientista encontrou essas verdades que estavam já antes [...]. Então, não fazer essa discussão que eu chamo de epistemológica [...] é incorrer na possibilidade de depois o futuro professor chegar à escola e quem sabe já desenvolver um experimento com os 
estudantes, esperando que eles também descubram aquilo que o químico já descobriu [...].” (P2)

Como mencionamos, a explicitação do conhecimento discente é um ato imperativo em uma prática docente dialógica e problematizadora (Freire, 1996). Embora o formador possa prever as visões discentes sobre a experimentação, é importante proporcionar um momento no qual os alunos exponham seus entendimentos em torno do assunto, a fim de que sejam problematizados no grande grupo. Essa problematização pode contribuir para criar entre os estudantes a necessidade de apropriação de um conhecimento inédito para eles (Delizoicov, 2005) que, de acordo com o fragmento acima, estaria relacionado com questões epistemológicas da experimentação.

Outra discussão de cunho epistemológico se baseia no conhecimento inicial dos alunos a respeito da relação entre teoria e prática:

"[...] no início, a linguagem dos nossos alunos é essa, fazer uma experiência [...] pra ilustrar, depois da teoria. Então, a gente sempre discute essa questão: que significado tem fazer um experimento depois da teoria [...]. Pra fazer com que os alunos deixem de serem ingênuos em relação a esse aspecto [...].” (P4)

A importância de abordar as diferentes compreensões epistemológicas sobre a relação entre teoria e prática se assenta nas facetas que a experimentação pode assumir. Ou seja, há aquela, assinalada pelo formador, na qual a experimentação tem a função de ilustrar uma teoria estudada previamente ou, no outro extremo, a que acredita na experiência sensível como fonte do conhecimento. Ambas as formas de entender as atividades experimentais parecem estar presentes entre docentes de química da educação superior (Gonçalves; Marques, 2013). A apreensão dessa contradição entre os licenciandos poderia constituir um tema a ser abordado na formação inicial de professores.

Enfim, os conhecimentos iniciais dos estudantes da licenciatura quanto à experimentação são um dos pontos de partida para os formadores selecionarem os assuntos relativos a esse conteúdo. O enfoque epistemológico defendido pelos formadores, por exemplo, fundamenta-se nas visões dos licenciandos a respeito do papel das atividades experimentais. Com base no viés freiriano, ressalta-se a importância de se problematizar o conhecimento deles com vistas a favorecer a aprendizagem em torno da experimentação.

\section{0 movimento contra-hegemônico em relação aos experimentos ilustrativos}

Identificaram-se indicativos de abordagens que visam combater entendimentos sobre as atividades experimentais como simples modo de ilustrar a teoria estudada previamente. Essas abordagens não são recentes segundo parte dos formadores. Por exemplo, a abordagem dos experimentos por redescoberta já possuía a intenção de ultrapassar a perspectiva puramente ilustrativa:

"Teve uma fase que eu talvez não tivesse tanta consciência sobre algumas questões [...]. A gente trabalhou muito com esta ideia da redescoberta [...] sempre esta ideia de um ensino ativo, que o aluno fosse o agente, que ele fosse o sujeito do processo [...]. Até a gente tomar consciência de que isso era um pouco ingênuo [...].” (P4)

O formador traz à tona a influência dos difundidos projetos de educação científica estadunidenses e ingleses na abordagem da experimentação no cenário brasileiro de formação de professores de química e das demais áreas das ciências da natureza, de modo geral. A crença na redescoberta dos conhecimentos da ciência por intermédio da experimentação era uma voz pujante em tais projetos mundialmente disseminados. Com influência da visão de Bachelard (1996) acerca da construção do conhecimento científico, afirma-se que a redescoberta, como uma proposta para desenvolver experimentos, constitua-se, talvez, em uma espécie de erro epistemológico. Com a intenção de incutir e transformar as atividades experimentais no ensino de ciências de forma que valorizassem a participação dos estudantes como sujeitos cognoscentes, os formadores contribuíram na difusão de entendimentos problemáticos sobre o papel da experimentação.

Propostas mais contemporâneas são abordadas pelos docentes das componentes curriculares integradoras:

"Uma coisa que eu tenho usado muito com eles [são sítios da Internet] e tem muitos bancos de experimentos, tem as experimentotecas, $o$ [centro de divulgação $\mathrm{X}]$ também tem experimentoteca. Então, esses alunos copiam essas coisas, trazem essas práticas e a gente discute. Como é que a gente pode adequar? Como é que eu posso acoplar isso com resolução de problema [...]?” (P3)

A articulação entre experimentos e atividades de resolução de problemas é uma das possibilidades de se distanciar dos chamados experimentos ilustrativos, e há certa diversidade de proposições na literatura relativa a experimentos por meio de resolução de problemas (Hofstein et al., 2005; Reigosa Castro; Jiménez Aleixandre, 2000; Gil Pérez et al., 1999). A ferramenta computacional tem sido apontada como uma aliada nessa articulação, visto que pode colaborar em diversos aspectos, a saber: monitoramento e controle dos experimentos; estudo ou investigação de um número maior de fenômenos em comparação às atividades experimentais de bancada; e utilização de técnicas inacessíveis se não fosse a 
presença do computador (Hodson, 1998). A experimentação na perspectiva da resolução de problemas pode contribuir, ao contrário dos experimentos puramente ilustrativos, para os estudantes realizarem previsões e analisarem resultados. Soma-se a isso o fato de poder favorecer a disseminação do entendimento de que a(s) resposta(s) a uma pergunta pode(m) ser obtida(s) por meio de diferentes métodos etc. Todavia, chama-se a atenção para a necessidade de não caracterizar de forma reducionista a resolução de problemas, uma vez que tal resolução, em geral, não se restringe ao desenvolvimento de atividades experimentais.

Outro formador expressa um exemplo de abordagem que se aproxima do exposto por uma perspectiva dialógica e problematizadora de educação:

"[...] procuramos trabalhar a experimentação sempre vinculada a fenômenos próximos do aluno, que tenha significado pra vida do aluno, e nós procuramos trabalhar sempre com uma problematização [...]. Problematizar a realidade [...] que o aluno presencia $[. .$.$] e, ao mesmo tempo, problematizar o$ conhecimento do aluno. Quer dizer, problematizar a interpretação que o aluno faz da realidade [...]. Trabalhar com objeto de conhecimento que tenha significado pro sujeito, que tenha relação com o cotidiano e numa abordagem sempre de problematização [...].” (P4)

Subjacente à proposta citada pelo investigado, parece estar a preocupação em desenvolver um experimento acerca de determinado assunto associado à realidade discente. De certa forma, aqui reside o objetivo de determinadas perspectivas de resolução de problemas frente à necessidade de promover problemas autênticos, isto é, aqueles que se caracterizam, dentre outros aspectos, por serem de um contexto próximo dos alunos (Reigosa Castro; Jiménez Aleixandre, 2000). Não se desconsidera a polissemia presente em expressões como "contexto próximo dos alunos" ou "cotidiano", termo utilizado pelo pesquisado. Em um viés dialógico e problematizador, tais expressões estão vinculadas à realidade local dos sujeitos, que seria o ponto de partida até se chegar a um contexto mais global (Freire, 2005). De outra parte, esse viés procura, como mencionou o formador, "problematizar a interpretação que o aluno faz da realidade" - realidade no sentido exposto acima. Isso não se constitui em um consenso na multiplicidade de propostas de atividades experimentais associadas à resolução de problemas tratada na literatura, e tampouco parece ser um ponto de discussão pelo menos em grande parte dos trabalhos relativos a essa modalidade de experimento. No relato, aparece ainda a apreensão do conhecimento discente como uma condição essencial, pois o que se pretende é problematizar, simultaneamente, os conhecimentos dos estudantes concernentes à realidade e à própria realidade.
Portanto, ao longo dos anos, os formadores procuraram, de diferentes formas, transcender a ideia da experimentação como um simples modo de ilustrar os conhecimentos teóricos estudados previamente. As sugestões de experimentos por redescoberta já eram uma tentativa contra a hegemonia dos experimentos ilustrativos ou de pura comprovação. Recentemente, a associação entre experimentos e atividades de resolução de problemas foi impulsionada com a divulgação de trabalhos na literatura, mas que não obrigatoriamente estão em sintonia absoluta com um viés educacional dialógico e problematizador de educação.

\section{A abordagem da experimentação relacionada com a história e a epistemologia da ciência}

Os formadores citaram que parte dos conteúdos abordados se relaciona com a história e a epistemologia da ciência. A discussão de entendimentos de ciências vinculados à experimentação, a partir de um viés epistemológico, é uma das ações docentes:

\begin{abstract}
"O que a gente tem abordado [...] é, por exemplo, concepção de ciências, não é? Tentando tirar esse caráter da verificação na experimentação, tentando fazer experimentação mais dialógica.” (P1)
\end{abstract}

A tese de que as ideias dos estudantes sobre a natureza da ciência podem influenciar sua atuação na realização dos experimentos tem sido tratada na literatura (Leach, 2002a), e nisso se assenta a importância de que os formadores as apreendam e discutam. Gil Pérez et al. (2001) reforçam que as visões problemáticas dos professores a respeito do trabalho científico não se reduzem a empírico-indutivista. Os autores apontam também: a rígida (algorítmica, exata, infalível etc.); a aproblemática e a-histórica; a exclusivamente analítica; a acumulativa de crescimento linear dos conhecimentos; a individualista e elitista da ciência; e a descontextualizada, socialmente neutra da ciência. Com exceção dos entendimentos empírico-indutivista e aproblemático e a-histórico, os demais não foram explicitamente sinalizados como objeto de discussão pelos formadores, o que obviamente não minimiza a relevância de suas discussões em torno de tais visões.

Sobre a natureza do debate a respeito de um entendimento empírico-indutivista, um formador expõe:

"Mas a discussão epistemológica do uso da experimentação, se ela tem o foco empírico, o quanto ela é indutivista, o quanto suas conclusões são indutivistas ou não, que tipo de tratamento eu posso não indutivista conferir a uma atividade prática, isso, na verdade, está inserido nos artigos [...]. Como é que eu posso criar uma atividade de laboratório e não 
ser puramente empirista [...]. Quem vem primeiro [...] A teoria ou a atividade experimental?" (P3)

No relato, evidencia-se a discussão epistemológica sobre a origem do conhecimento. Nesse sentido, é importante registrar o que defende a epistemologia contemporânea. Ou seja, se a gênese do conhecimento não é a experiência sensível, como pressupõe o empirismo, também não parece adequado atribuí-la exclusivamente à razão, visto que não se desconsidera o papel que o empírico possui na construção do conhecimento (Bachelard, 1996). Valorizar o papel do empírico na construção do conhecimento em dissonância com o empirismo, como é a posição assumida pelo formador, não significa necessariamente se alijar de outras visões problemáticas do trabalho científico e da experimentação como apontado anteriormente.

Outro formador sinaliza a discussão sobre a não neutralidade na observação do experimento:

"Sempre procurar desenvolver, por parte deles, esse entendimento de que o conhecimento em sala de aula com experimento, ele não é feito, assim, de forma empiricista-indutivista, a partir da observação sensorial, e eu vou enxergar a teoria lá [...]. A teoria que eu digo é pensando nos modelos teóricos [...].” (P2)

A necessidade de apropriação de conhecimentos científicos para observar cientificamente é advertida por representantes da moderna filosofia da ciência, a exemplo de Hanson (1975). No entanto, a não apropriação desses conhecimentos não faz da observação um processo neutro. Caso contrário, acreditar-se-ia nos sujeitos como tábulas rasas e, por conseguinte, em dados puros oriundos da experiência sensível.

Uma abordagem histórica da experimentação também foi indicada pelos formadores: "A questão da experiência também como uma perspectiva histórica [...], Discutindo o papel da experiência no desenvolvimento da própria química como ciência, desde a alquimia, enfim, como foi importante a experimentação" (P4). Abordar a experimentação sob o olhar da história da ciência é um modo de não a reduzir a um recurso didático. Na problematização da natureza epistemológica dos experimentos, é relevante situá-los na totalidade do trabalho científico, a fim de que se ensine a respeito do trabalho dos cientistas hoje e no passado, inclusive acerca das transformações na linguagem científica ao longo dos anos e como a experimentação contribuiu para tal (Sutton, 2002). O apoio da abordagem histórica da experimentação na epistemologia contemporânea é importante para não incorrer em interpretações pouco coerentes das práticas científicas.

Assim, os formadores expressaram as discussões epistemológicas que promovem no estudo da experimentação. O combate à visão empírico-indutivista é amplamente exercitado, mas não ficou explícito o enfrentamento a outras visões problemáticas quanto à construção do conhecimento científico, em geral, e à experimentação, em particular. Uma abordagem histórica das atividades experimentais foi igualmente citada como importante.

\section{Conhecimentos sobre a experimentação: permanências e transformações}

Os formadores comentaram a respeito das aprendizagens dos licenciandos em relação à experimentação no ensino de química. Na compreensão de parte dos formadores, tal aprendizagem é caracterizada por uma morosidade: "[licenciandos] atuam nessa perspectiva [da comprovação], porque é muito forte, precisa de um trabalho de muito tempo para que isso possa ser mexido [...]” (P1). O comentário do formador sugere uma reflexão acerca da contribuição da formação inicial na aprendizagem dos licenciandos concernente à experimentação e de outros assuntos pertinentes à docência. Apesar de os licenciandos não abandonarem seus conhecimentos iniciais, é imperativa a apropriação de conhecimentos novos a partir da interpretação de uma perspectiva progressista de educação. Isso está mais explícito em outro relato:

"Eles chegam com essa visão e eu não sei até que ponto a gente consegue mudá-las. Em alguns casos, a gente percebe isso de uma forma bem clara. Em outros, a gente vê que não atinge muito, porque o aluno [...] ele vê que a gente tem um discurso, se a gente cobra isso numa avaliação, numa forma de agir, ele responde do jeito que sabe que a gente quer ouvir. Mas isso não quer dizer, muitas vezes, que ele vai mudar a visão dele ou que ele vai mudar a prática [...].” (P5)

A apropriação de novos conhecimentos não implica o abandono de outros conhecimentos, por isso, tal abandono não deveria se constituir no objetivo do formador, e sim a apropriação do conhecimento sistematizado. Como expõe Freire (1977), somente a ingenuidade tecnicista desconsidera a permanência dos antigos conhecimentos no processo de apropriação de novos. Ao se contrapor tacitamente a uma visão que se aproxima de um relativismo - uma vez que, ao considerar a permanência de conhecimentos relacionados ao senso comum, não defende que estes tenham, obrigatoriamente, o mesmo potencial que aqueles sistematizados no enfrentamento de problemas -, o conhecido educador brasileiro assinala a importância da transformação dos conhecimentos. Portanto, a ideia de não abandono não significa a opção por um entendimento exclusivamente continuísta do processo de construção do conhecimento (Freire, 1977). Outro formador percebe as permanências e as transformações de forma mais explícita:

"Aquele aluno que passou todo o tempo apenas fazendo 'feijão com arroz', ele normalmente é mais 
limitado [...]. Aquele que realmente se envolve, que vai, que faz, que participa, que discute, que reflete, ele é diferenciado [...]. E como nós trabalhamos com [essa proposta] desde o terceiro nível, quando eles chegam ao estágio, eles já chegam diferenciados [...], já chegam com uma autonomia maior, já querendo fazer atividade diferenciada. Por que antigamente o que acontecia? Eles chegavam ao estágio e não tinham passado por tudo isso." (P4)

A transformação dos conhecimentos discentes a respeito da experimentação pode estar associada, segundo sugere implicitamente o investigado, com a reforma curricular na licenciatura, de modo que os licenciandos possam interagir com a escola mais intensamente durante a formação inicial. Isso se opõe aos cursos orientados mais fortemente pela racionalidade técnica, cuja interação com a escola ocorre na fase terminal; o que atribui à prática um papel secundário na formação.

$\mathrm{O}$ que se espera que os licenciandos aprendam sobre a experimentação e a avaliação dessa aprendizagem são assuntos pertinentemente apontados: "Eu não vejo que, com a formação inicial, eles já tenham feito a ruptura definitiva com essa concepção primeira [...]. Mas eles iniciam a vivência dessa reflexão [...]. É um objeto de aprendizagem [...] experimentação no ensino da química" (P2). Explicita-se a dificuldade de avaliar as aprendizagens referentes à experimentação. A ideia de que não há abandono não significa um consentimento à pura permanência dos conhecimentos iniciais, pois implicaria a aceitação de uma visão antidialógica, tal como aquela que impõe os conhecimentos sistematizados sem considerar o conhecimento inicial (Delizoicov, 1991).

Portanto, os formadores parecem entender a aprendizagem dos licenciandos quanto à experimentação como um processo com permanências e transformações. Reconhecem que os graduandos não abandonam seus conhecimentos iniciais acerca da experimentação, assim como há aprendizagens endossadas nas contribuições contemporâneas relativas ao assunto. Promover a problematização dos conhecimentos acerca das atividades experimentais significa romper com a ideia de que a pura permanência dos conhecimentos iniciais relativos ao tema é algo admissível nos processos de formação docente.

\section{Conclusões}

Com base no exposto, os formadores participantes da pesquisa sinalizaram importantes elementos como pontos de reflexão, os quais estão além da necessidade de enfrentar as visões empiristas relativas à experimentação presentes entre os docentes de ciências da natureza, como tem sido reivindicado, de forma recorrente, pelas pesquisas acerca das atividades experimentais (Leach, 2002b) ou sobre a prática pedagógica dos formadores de componentes curriculares integradoras (Silva; Schnetzler, 2005). Os comentários dos formadores acerca da experimentação, sobretudo em torno dos conhecimentos dos licenciandos - e até dos professores da educação básica -, reforçam a necessidade da problematização das atividades experimentais na formação de professores e no ensino de ciências. Algo que precisa ocorrer também no desenvolvimento profissional dos formadores de professores de ciências, especialmente daqueles que lecionam em componentes curriculares de conteúdo específico. As contribuições desse desenvolvimento profissional para a aprendizagem sobre a natureza pedagógica da experimentação precisam ser investigadas como forma de sinalizar modos mais efetivos de enfrentar o problema aqui caracterizado.

A presença de contradições nos conhecimentos ou nas ações dos participantes dos cursos de licenciatura em ciências da natureza acerca da experimentação aponta uma perspectiva diferente para a atuação didática dos formadores de professores - e também para a pesquisa -, descentralizando a atenção da apreensão de entendimentos dos sujeitos em torno do papel ou dos objetivos das atividades experimentais, dimensão largamente investigada. Às vezes, as contradições podem ser indicativas de limitações no conhecimento dos sujeitos e, por isso, precisam ser problematizadas, de modo que a apreensão das contradições relativas às atividades experimentais ganhe maior destaque nos processos formativos. As contradições podem estar vinculadas a situações significativas que contribuem para contextualizar o que é estudado acerca da experimentação. Sobre a noção de permanência e transformações relativas aos conhecimentos sobre experimentação dos licenciandos em química, os resultados da pesquisa sinalizam a necessidade de melhor compreender como evoluem os conhecimentos desses sujeitos acerca da questão.

Ainda que as situações-limite caracterizadas tenham relação com as influências da racionalidade técnica sobre a formação de professores, é preciso compreendê-las como constituintes de um complexo processo que transcende tais influências. Elas são dimensões concretas e históricas de determinada realidade e sua superação em direção a um inédito viável envolve um processo formativo que não está dado, apesar dos indicativos dos formadores e de outros trabalhos presentes na literatura. $\mathrm{O}$ referencial progressista explorado para investigar a temática da experimentação articulada com a formação docente favoreceu a compreensão de determinados problemas relacionados com situações-limite de uma forma não negativa, visto que, nesse referencial, as situações-limite não são barreiras insuperáveis. Deriva disso uma das possíveis implicações dessa pesquisa que poderia ser o investimento em investigações que pudessem colaborar na elucidação do inédito viável em relação à apropriação da experimentação no ensino, na qualidade de um conteúdo do desenvolvimento profissional dos formadores de professores de química - sejam eles atuantes em componentes curriculares de conteúdos específicos ou integradoras -, bem como das suas práticas docentes. Por outro lado, reforça-se que as situações-limite aqui apontadas, somadas aquelas caracterizadas em 
Gonçalves e Marques (2013), são importantes de serem problematizadas com os formadores de professores de química, de maneira a favorecer o vislumbramento do inédito viável.

Parte dos relatos dos formadores indicou que, às vezes, o estudo das atividades experimentais na formação inicial de professores está em sintonia com os pressupostos de uma perspectiva progressista, sobretudo quando se busca dialogar com o conhecimento inicial dos licenciandos. Assim, considera-se que o depoimento dos formadores sinalizou, em alguma medida, modos de desenvolver uma formação docente em harmonia com uma perspectiva progressista, de modo a favorecer a problematização da experimentação na qualidade de um conteúdo da formação inicial de professores de química/ ciências da natureza. A problematização reconhece as aprendizagens em torno do referido conteúdo como um processo que envolve permanências e transformações, rompendo com visões tecnicistas do processo de apropriação do conhecimento. Nisso fica implícita a importância de se investigar de forma mais detalhada como os licenciandos se apropriam de conhecimentos sobre a experimentação. Cumpre notar, entretanto, a presença de determinados silêncios entre os formadores, uma vez que não mencionaram, por exemplo, o estudo da experimentação na perspectiva da chamada educação inclusiva - experimentos para estudantes cegos, surdos etc. Isso pode ser um indicativo de temáticas para as pesquisas e a atuação dos formadores, imperativas, diga-se de passagem, no atual cenário.

\section{Referências}

AFONSO, A.S.; LEITE, L. Concepções de professores de ciências físico-químicas sobre a utilização de atividades laboratoriais. Revista Portuguesa de Educação, v.13, n.1, p. 185-208, 2000.

ANTÚNEZ, G.C.; PÉREZ, S.M.; PETRUCCI, D. Concepciones de los docentes universitarios sobre los trabajos prácticos de laboratorio. Revista Brasileira de Pesquisa em Educação em Ciências, v. 8, n. 1, p. 1-17, 2008.

AULER, D.; MUENCHEN, C.; FORGIARINI, M.S.; GEHLEN, S.T.; GRIEBELER, A.; SANTINI, E.L.; STRIEDER, R.B.; VEDOOTO SCHENEIDER C. Transporte particular x coletivo: intervenção curricular pautada por interações entre ciência-tecnologia-sociedade. Enseñanza de las Ciencias, n. extra, p. 1-5, 2005.

BACHELARD, G. A formação do espírito científico: contribuição para uma psicanálise do conhecimento. Rio de Janeiro: Contraponto, 1996.

BAZZO, V. L. Constituição da profissionalidade docente na educação superior: desafios e possibilidades. 2007. Tese (Doutorado em Educação) - Universidade Federal do Rio Grande do Sul, Porto Alegre, 2007.

BENARROCH, A.; MARÍN, N. Relaciones entre creencias sobre enseñanza, aprendizaje y conocimiento de ciencias. Enseñanza de las Ciencias, v. 29, n.2, p. 289-304, 2011.

BRZEZINSKI, I. Formação de profissionais da educação (1997-2002). Brasília: Ministério da Educação; INEP, 2006.
CAMPANARIO, J.M. Contra algunas concepciones y prejuicios comunes de los profesores universitarios de Ciencias sobre la didáctica de las Ciencias. Enseñanza de las Ciencias, v. 21, n. 2, 319-328, 2003.

COELHO, J.C. A chuva ácida na perspectiva de tema social: um estudo com professores de Química em Criciúma (SC). 2005. Dissertação (Mestrado em Educação Científica e Tecnológica) - Universidade Federal de Santa Catarina, Florianópolis, 2005.

DELIZOICOV, D. Conhecimento, tensões e transições. 1991. Tese (Doutorado em Educação) - Universidade de São Paulo, São Paulo, 1991.

Formação inicial de professores de Física. Educação em Foco, v. 5 , n. 1, p. 73-84, 2000.

Problemas e problematizações. In: PIETROCOLA, M. (Org.). Ensino de física: conteúdo, metodologia e epistemologia em uma concepção integradora. Florianópolis: Ed. UFSC, 2005, p. 125-150.

La educación en ciencias y la perspectiva de Paulo Freire. Alexandria: Revista de Educação em Ciência e Tecnologia, v. 1, n. 2, p. 37-62, 2008.

FRANCISCO, C.A.; QUEIROZ, S.L. A produção do conhecimento sobre ensino de química nas Reuniões Anuais da Sociedade Brasileira de Química: uma revisão. Química Nova, v. 31, n. 8, p. 2100-2110, 2008.

FREIRE, P. Extensão ou comunicação? Rio de Janeiro: Paz e Terra, 1977. Criando métodos de pesquisa alternativa: aprendendo a fazêla melhor através da ação. In: BRANDÃO, C.R. (Org.). Pesquisa participante. 4. ed. São Paulo: Brasiliense, 1981, p. 34-41.

Pedagogia da autonomia: saberes necessários à prática educativa. 30. ed. São Paulo: Paz e Terra, 1996.

Pedagogia do oprimido. 40. ed. Rio de Janeiro: Paz e Terra, 2005.

FREIRE, P.; SHOR, I. Medo e ousadia: o cotidiano do professor. Rio de Janeiro: Paz e Terra, 1986.

GEHLEN, S.T.; AUTH, M.A.; AULER, D. Contribuições de Freire e Vygotsky no contexto de propostas curriculares para a Educação em Ciências. Revista Electrónica de Enseñanza de las Ciencias, v. 7, n. 1, p. 63-85, 2008.

GIL PÉREZ, D.; FURIÓ MÁS, C.; VALDÉS, P.; SALINAS, J.; MARTÍNEZ-TORREGROSA, J.; GUISOLA, J.; GONZÁLES, E.; DUMAS-CARRÉ, A.; GOFFARD, M.; CARVALHO, A.M.P. $¿$ Tiene sentido seguir distinguiendo entre aprendizaje de conceptos, resolución de problemas de lápiz y papel y realización de prácticas de laboratorio? Enseñanza de las Ciencias, v. 17, n. 2, p. 311-320, 1999.

GIL PÉREZ, D.; MONTORO, I.F.; ALÍS, J.C.; CACHAPUZ, A.; PRAIA, J. Para uma imagem não deformada do trabalho científico. Ciência \& Educação, v. 7, n. 2, p. 125-153, 2001.

GONÇALVES, F. P.; MARQUES, C. A Problematización de las actividades experimentales en la formación y la práctica docente de los formadores de profesores de Química. Enseñanza de las Ciencias, v. 31, n. 3, p. 67-86, 2013.

GONÇALVES, F.P.; MARQUES, C.A. A circulação inter e intracoletiva de conhecimento acerca das atividades experimentais no desenvolvimento profissional e na docência de formadores de 
professores de química. Investigações em Ensino de Ciências, v. 17, n. 2, p. 467-488, 2012a.

. A problematização das atividades experimentais na educação superior em química: uma pesquisa com produções textuais docentes - parte II. Química Nova, v. 35, n. 4, p. 837-843, 2012 b.

. A problematização das atividades experimentais na educação superior em química: uma pesquisa com produções textuais docentes. Química Nova, v. 34, n. 5, p. 899-904, 2011.

GRANDINI, N.A.; GRANDINI, C.R. Os objetivos do laboratório didático na visão dos alunos do curso de licenciatura em física da UNESP-Bauru. Revista Brasileira de Ensino de Física, v. 26, n. 3, p. 251-256, 2004.

HANSON, N.R. Observação e interpretação. In: NAGEL, E.; MORGENBESSER, S. Filosofia da ciência. São Paulo: Cultrix, 1975, p. 127-138.

HIRVONEN, P.E.; VIIRI, J. Physics student teachers' ideas about the objectives of practical work. Science \& Education, v. 11, n. 3, p. 305-316, 2002.

HODSON, D. Hacia un enfoque más crítico del trabajo de laboratorio. Enseñanza de las Ciencias, v. 12, n. 3, p. 299-313, 1994.

. Is This really what scientists do seeking a more authentic science and beyond the school laboratory. In: WELLINGTON, J. Practical work in school science: which way now? London: Routledge, 1998, p. 93-108.

HOFSTEIN, A.; NAVON, O.; KIPNIS, M.; NAAMAN-MAMLOK, R. Developing student' ability to ask more and better questions resulting from inquiri-type chemistry laboratories. Journal of Research in Science Teaching, v. 42, n. 7, p. 791-806, 2005.

HOFSTEIN, A.; MAMLOK-NAAMAN, R. The laboratory in science education: the state of the art. Chemistry Education Research and Practice, v. 8, n. 2, p. 105-107, 2007.

LEACH, J. Student's understanding of the nature of science and its influence on labwork. In: PSILLOS, D.; NIEDDERER, H. (Org.). Teaching and learning in the science laboratory. Dordrecht: Kluwer, 2002a, p. 41-48.

LEACH, J. The use of secondary data in teaching about data analysis in a first year undergraduate biochemistry course. In: PSILLOS,
D.; NIEDDERER, H. (Org.). Teaching and learning in the science laboratory. Dordrecht: Kluwer, 2002b, p. 165-178.

MARTÍNEZ, J.J.B.; BENARROCH, A.B. Coherencia epistemológica entre ciencia, aprendizaje y enseñanza de profesores universitarios colombianos. Comparación de resultados con profesores chilenos y españoles. Enseñanza de las Ciencias, v. 31, n. 2, p. 55-74, 2013.

MORAES, R.; GALIAZZI, M.C. Análise textual discursiva. Ijuí: Ed. Unijuí, 2007.

PSILLOS, D.; NIEDDERER, H. (Org.). Teaching and learning in the science laboratory. Dordrecht: Kluwer, 2002.

REIGOSA CASTRO, C.E.; JIMÉNEZ ALEIXANDRE, M.P. La cultura científica en la resolución de problemas en el laboratorio. Enseñanza de las Ciencias, v. 18, n. 2, p. 275-284, 2000.

SANTOS, W.L.P. Scientific literacy: a freirean perspective as a radical view of humanistic science education. Science Education, v. 93, n. 2, p. 361-382, 2009.

SCHNETZLER, R.P. Pesquisa em ensino de química no Brasil: conquistas e perspectivas. Química Nova, v. 25(S1), p. 14-24, 2002.

SILVA, R.M.G.; SCHNETZLER, R.P. Constituição de professores universitários de disciplinas sobre o ensino de Química. Química Nova, v. 28, n. 6, p. 1123-1133, 2005.

SILVA, R.R.; MACHADO, P.F.L. A experimentação no ensino médio de química: a necessária busca da consciência ético-ambiental no uso e descarte de produtos químicos - um estudo de caso. Ciência \& Educação, v. 14, n. 2, p. 233-249, 2008.

SUTTON, C. Los profesores de ciencias como profesores de lenguaje. Enseñanza de las Ciencias, v. 21, n. 1, p. 21-25, 2002.

TORRES, J.R.; GEHLEN, S.; MUENCHEN, C.; GONÇALVES, F.P.; LINDEMANN, R.H.; GONÇALVES, F.J.F. Ressignificação curricular: contribuições da investigação temática e da análise textual discursiva. Revista Brasileira de Pesquisa em Educação em Ciências, v. 8, n. 2, p. 1-13, 2008.

WELLINGTON, J. (Org.) Practical work in school science: which way now? London: Routledge, 1998.

ZABALZA, M.A. O ensino universitário: seu cenário e seus protagonistas. Porto Alegre: Artmed, 2004. 